\title{
BALANÇO DE RADIAÇÃO E FLUXO DE CALOR NO SOLO EM AMBIENTE NATURAL E PROTEGIDO CULTIVADO COM PEPINEIRO ${ }^{(1)}$
}

\author{
EMERSON GALVANI (2); JOÃO FRANCISCO ESCOBEDO ${ }^{(2)}$; \\ ANDRÉ BELMONT PEREIRA ${ }^{(3)}$
}

\begin{abstract}
RESUMO
São descritos os níveis desal do de radiação, radiação gl obal efluxo de calor do/ para o solo dentro e fora de estufas com cobertura de polietileno na época de outono-inverno e na de primavera-verão. Ao longo dos ciclos do experimento, os ambientes foram cultivados com pepineiro, cultivar Aoday, variedadeH okuroo, decrescimento indeterminado. Com basenos resultados, conclui-sequeem estufa coberta com polietileno, a intensidade de incidência de energia solar por unidade de área diminui durante o período diurno, assim como as perdas por emissão, duranteo período noturno. A transmissividade do polietileno foi alterada em função da época do ano e do tempo de exposição do material, passando de $70,8 \%$, no inverno, para $74,9 \%$, no verão. O fluxo de calor do/ para o solo no ciclo de primavera-verão foi dependente do índice de área foliar da cultura.

Palavras-chave: balanço de radiação, ambiente protegido, fluxo de cal or no solo, radiação solar gl obal, pepineiro.
\end{abstract}

\section{ABSTRACT \\ NET RADIATION AND SOIL HEAT FLUXIN NATURAL AND PROTECTED ENVIRONMENTSCROPPED WITH CUCUMBER}

Net radiation, global solar radiation and heat flux from/ to the soil both inside and outside greenhouses with polyethylene cover throughout the fall-winter and spring-summer seasons have been assessed at the research station of the Universidade Estadual Paulista, Campus of Botucatu, State of São Paulo, Brazil. Throughout the cycles of the experiment, both environments scrutinized in the current study were cultivated with cucumber crop - Aoday, Hokuroo - a variety of undetermined growth habit. The results indicated that the greenhouse with polyethylene cover tended to decrease the intensity of solar radiation incidence per unity of area throughout the diurnal period, as well as losses from emission during thenighttime. Thetransmissivity of polyethylenewasaltered as afunction of the day of the year and exposition time of the material, changing from $70.8 \%$ at the winter to $74.9 \%$ at the summer seasons. The heat flux from/ to the soil during thespring-summer cyclewas dependent of the leaf area of the crop.

Key words: net radiation, protected environment, soil heat flux, global solar radiation, cucumber crop.

\section{INTRODUÇÃO}

O saldo de radiação representa a energia disponível aos processos físicos e biológicos que ocorrem na superfícieterrestre. Essa energia éa diferença entreos fluxos totais da radiação incidenteea "perdida" (emitida e/ ou refletida) por uma superfície, medida,

(1) Parte da tese de doutorado do primeiro autor, em Energia na Agricultura, apresentada à Faculdade de Ciências Agronômicas, Universidade Estadual Paulista (FCA/ UNESP), Botucatu (SP). Recebido para publicação em 27 de dezembro de 2000 e aceito em 5 de junho de 2001.

( $\left.{ }^{2}\right)$ Departamento de Recursos Naturais (FCA/ UNESP), Câmpus Lageado, Caixa Postal 237, 18603-970 Botucatu (SP). E-mail: galvani@fca.unesp.br

(3) Departamento de Solos e Engenharia A grícola, Universidade Estadual de Ponta Grossa (UEPG-PR). E-mail: abelmont@uepg.br 
normalmente, em plano horizontal. Ao longo do dia, nas horas de brilho solar, o saldo de radiação em uma superfície qualquer tende a ser positivo, pois os fluxos incidentes (global e atmosférico) são superiores às frações refletidas e emitidas. Por outro lado, durante a noite, é comum que esses valores sejam negativos, pois o fluxo incidente passa a ser apenas atmosférico e a energia emitida pela superfície, superior a este, resultando em um saldo de radiação negativo (GEIGER, 1961; Monteith e Unsworth, 1990; Pezzopane et al., 1995).

Para as condições de estufa com cobertura de polietileno, os valores de saldo de radiação são, em geral, menores que os externos, devido à absorção e reflexão de uma fração da radiação direta pelo polietileno, contudo, em condições de saldo de radiação negativo (à noite), os valores externos revelam-se maiores, ou seja, há maior perda de energia para a atmosfera que para o meio interno em virtude, justamente, da contra-irradiação do polietileno que impede a passagem do componente da radiação de onda longa. Segundo Tapia (1981) e Robledo de Pedro e Vicente (1988), o polietileno de baixa densidade (PEBD) apresenta transmissividade de onda longa até de $80 \%$; a retenção dessas ondas seria, portanto, pequena. Apesar da alta transparência, BuRiol et al. (1993) afirmam que, em noites de temperaturas baixas, uma pequena redução na perda de energia pode ser significativa nas taxas de resfriamento do ar.

AzEvEDo et al. (1997) concluíram, para estudos de balanço de energia e estimativa de evapotranspiração potencial da cultura da videira, na região de Petrolina (PE), que é possível estimar o saldo de radiação em função apenas da radiação solar global incidente com excelente precisão. GALVANI et al. (1998a) obtiveram, em estufas orientadas no sentido leste-oeste e nortesul cultivadas com alface, relação entre saldo de radiação $\left(W \cdot \mathrm{m}^{-2}\right)$ interno e externo a partir dos seguintes modelos: $\mathrm{SR}_{\mathrm{L}-\mathrm{O}}=0,853$. $\mathrm{SR}_{\text {ext }}\left(\mathrm{R}^{2}=0,93\right)$ e $\mathrm{SR}_{\mathrm{N}-\mathrm{S}}=$ $0,828 \cdot \mathrm{SR}_{\mathrm{ext}}\left(\boldsymbol{R}^{2}=0,98\right)$. GALVANI et al. $(1998 \mathrm{~b})$, para as mesmas condições, encontraram uma relação entre saldo de radiação em estufas leste-oeste e norte-sul de 0,576 e 0,558 respectivamente. SeNTELHAS et al. (1998) verificaram para as condições climáticas de Piracicaba (SP), sobre gramado, uma relação de 0,57 , ou seja, o saldo de radiação representa em termos energéticos $57 \%$ da componente da radiação global.

O objetivo do trabalho foi avaliar os níveis energéticos do saldo de radiação, da radiação global e do fluxo de calor do/para o solo em condição de estufa com cobertura de polietileno e no campo, em períodos de inverno e verão nas condições climáticas de Botucatu (SP). Objetivou-se, ainda, relacionar por modelos lineares o saldo de radiação e a radiação global entre os ambientes e entre os ciclos de cultivo.

\section{MATERIAL E MÉTODOS}

\subsection{Construção da estufa com cobertura de polietileno}

O experimento foi instalado em área experimental do Departamento de Recursos Naturais da Faculdade de Ciências Agronômicas (FCA/UNESP), Câmpus de Botucatu (SP) - latitude: $22^{\circ} 51^{\prime}$ S, longitude: $48^{\circ} 26^{\prime} \mathrm{W}$ e altitude: $786 \mathrm{~m}$. O ambiente protegido construído foi do tipo túnel, perfazendo uma área de $280 \mathrm{~m}^{2}$, com $7 \mathrm{~m}$ de largura por $40 \mathrm{~m}$ de comprimento e laterais a $2,2 \mathrm{~m}$ acima do nível do solo e arco central de $4 \mathrm{~m}$. O polietileno utilizado foi o de $120 \mu \mathrm{m}$ de espessura na cobertura e as laterais de "sombrite" a 50\% (Figura 1). A estufa foi orientada ao norte-sul geográfico.

O primeiro ciclo teve início em 13/5/98 e término em 10/9/98, denominado ciclo de outono-inverno. Para o período de primavera-verão, o transplantio foi realizado em 10/11/98 com o término do ciclo em 10/2/99. Nos canteiros, o espaçamento entre plantas na linha foi de $0,3 \mathrm{~m}$ e de $0,7 \mathrm{~m}$ entre linhas. Efetuou-se o controle de irrigação com base nos valores de evapotranspiração, obtidos por lisímetros de lençol freático constante, instalados dentro e fora das casas de vegetação. Seis lisímetros (três deles no interior e outros três, em condição externa), dispostos entre as parcelas de cultivo, forneceram, mediante a diferença entre duas leituras consecutivas, os valores de evapotranspiração da cultura, os quais foram repostos no dia seguinte pelo sistema de gotejamento. Desenvolveu-se um modelo de regressão linear entre vazão e tempo para os gotejadores.

A cultivar utilizada foi a Aoday, variedade Hokuroo (pepino Japonês - tipo salada de crescimento indeterminado). A escolha dessa variedade justifica-se

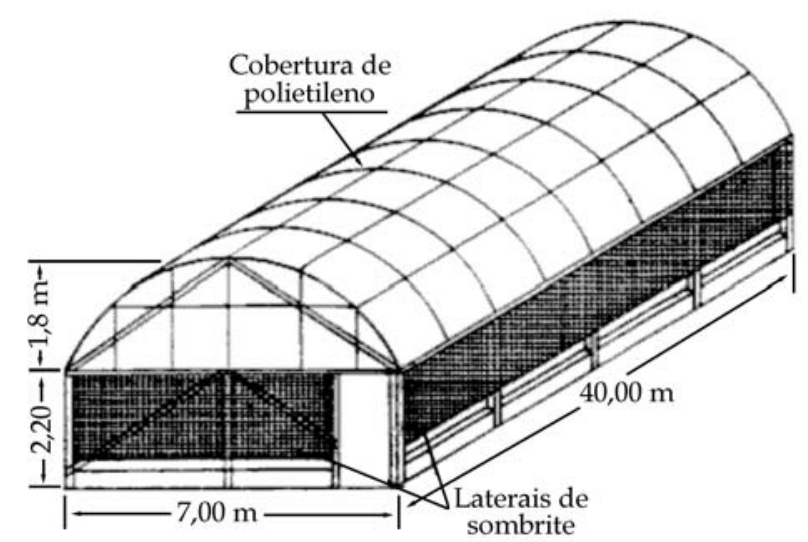

Figura 1. Esquema representativo do ambiente protegido por cobertura de polietileno. 
pelo elevado valor comercial, o que permite uma relação custo/benefício favorável para o cultivo em estufas, principalmente na entressafra (inverno).

\subsection{Instrumentos e técnica utilizados}

O saldo de radiação e o fluxo de calor do/para o solo foram monitorados por saldo radiômetros e fluxímetros fabricados pela Radiation Energy Bundget Systems, Inc. (REBS). Monitorou-se a radiação global com o auxílio de piranômetros montados e calibrados no laboratório de climatologia da Faculdade de Ciências Agronômicas de Botucatu, UNESP (Quadro 1).

Com a utilização dos fluxímetros determinam-se os ganhos e as perdas de energia do solo; valores positivos se dão quando o fluxo é da atmosfera para o solo e, negativos quando ocorre o inverso. Os fluxímetros foram instalados a $0,02 \mathrm{~m}$ de profundidade e o saldo de radiação e o sensor de radiação solar global a 2,2 m acima do solo, em ambas as condições. Obtiveram-se os valores de saldo de radiação, radiação global e fluxo de calor do/para o solo instantaneamente $\left(\mathrm{W} \cdot \mathrm{m}^{-2}\right)$ em intervalos de cinco segundos, com médias geradas a cada cinco minutos. Os totais de energia foram integrados ao longo do dia (MJ.m ${ }^{-2}$ ) e do ciclo da cultura. Conectaram-se os sensores a um coletor de dados automatizados micrologger.

\section{RESULTADOS E DISCUSSÃO}

\subsection{Saldo de radiação}

Na figura 2 observa-se uma curva típica do saldo de radiação nas condições climáticas do outono em Botucatu (SP), dentro e fora da estufa com cobertura de polietileno.

O saldo máximo de radiação, apresentado na figura 2, ocorreu às $11 \mathrm{~h} 30 \mathrm{~min}$ e às $12 \mathrm{~h} 25 \mathrm{~min}$, com valores de 405 e $557 \mathrm{~W} . \mathrm{m}^{-2}$ nas condições interna e externa respectivamente. A irradiância de ondas longas máxima foi -40,67 e -72,12 W.m. ${ }^{-2}$, ocorrendo às $17 \mathrm{~h} 55 \mathrm{~min}$ e às $18 \mathrm{~h}$, respectivamente, nas condições interna e externa, evidenciando significativa diminuição na emissão de ondas longas no meio interno (Figura 2).

A relação entre o saldo de radiação nos períodos diurno e noturno (SRdiurno/SRnoturno) em valor absoluto foi de $26,1 \%$ e $17,5 \%$ para as condições externa e interna respectivamente (Quadro 2). Associase essa relação inferior em condição interna à contra-irradiação do polietileno que, comumente, devolve parte da energia emitida pela superfície. $\mathrm{Na}$ figura 2B notam-se picos de menores valores de saldo de radiação, resultado do sombreamento dos sensores pelos arcos metálicos da estufa. Pode-se dizer que na
Quadro 1. Sensores para monitoramento do saldo de radiação, fluxo de calor no solo e radiação global e suas respectivas constantes ou fatores de calibração

\begin{tabular}{lcc}
\hline Sensor & $\begin{array}{c}\text { Ambiente } \\
\text { interno }\end{array}$ & $\begin{array}{c}\text { Ambiente } \\
\text { externo }\end{array}$ \\
\hline Saldo de radiação $^{(1)}$ & $9,14 \mathrm{~W} \cdot \mathrm{m}^{-2} \cdot \mathrm{mV}^{-1}$ & $13,5 \mathrm{~W} \cdot \mathrm{m}^{-2} \cdot \mathrm{mV}^{-1}$ \\
Fluxímetros $^{(1)}$ & $35,8 \mathrm{~W} \cdot \mathrm{m}^{-2} \cdot \mathrm{mV}^{-1}$ & $36,2 \mathrm{~W} \cdot \mathrm{m}^{-2} \cdot \mathrm{mV}^{-1}$ \\
Global $^{(2)}$ & $8,760 \mu \mathrm{V} \cdot \mathrm{m}^{2} \cdot \mathrm{W}^{-1}$ & $8,130 \mu \mathrm{V} \cdot \mathrm{m}^{2} \cdot \mathrm{W}^{-1}$ \\
\hline
\end{tabular}

( $\left.{ }^{1}\right)$ Fabricado pela Radiation Energy Bundget Systems, Inc. (REBS). $\left({ }^{2}\right)$ Equipamentos montados e calibrados no laboratório de climatologia da FCA/UNESP, Câmpus de Botucatu (SP).

estufa com cobertura de polietileno há diminuição da intensidade de incidência de energia por unidade de área no período diurno e, também, perdas por emissão à noite.

A figura 3 mostra as curvas de saldo de radiação para as condições interna e externa no período de máximo crescimento vegetativo da cultura de pepineiro em dia nublado (25/12/1998), para o qual se observa uma relação de $77,3 \%$ para o saldo de radiação. Nota-se que, em função da cobertura do céu, a emissão noturna é próxima a zero para os dois ambientes, diminuindo, assim, o efeito da cobertura de polietileno nessas condições.

\subsection{Fluxo de calor do/para o solo}

O fluxo de calor do/para o solo representa a fração do saldo de radiação que foi transferida para os níveis inferiores do solo e, geralmente, resulta em acréscimo de energia para o meio à noite, ou em diminuição, no período diurno. O fluxo de calor no solo (FCS) é função da temperatura em diferentes níveis e da condutividade térmica do solo, sendo influenciado diretamente pela variação da primeira. Em estudos de balanço de energia a quantificação do FCS torna-se importante, pois representará a entrada/saída de energia de determinado meio, contribuindo, assim, para o aumento e/ou redução nos fluxos de calor

Quadro 2. Comparação entre os valores de saldo de radiação obtidos no período diurno (SRdiurno), noturno (SRnoturno) e total (SR), dentro e fora de estufa com cobertura de polietileno, em 21/5/98

\begin{tabular}{lcc}
\hline Saldos & Condição externa & Condição interna \\
\cline { 2 - 3 } & \multicolumn{2}{c}{ MJ.m ${ }^{-2}$} \\
\hline SRdiurno & $+11,684$ & $+8,450$ \\
SRnoturno & $-3,052$ & $-1,477$ \\
SR & $+8,632$ & $+6,973$ \\
SRnot/SRdiu (\%) & 26,1 & 17,5 \\
\hline
\end{tabular}


latente e sensível e, conseqüentemente, aumentar e/ ou reduzir as taxas de evaporação e transpiração.

A figura 4 mostra as curvas de FCS em diferentes datas. Em 2/6/98 os valores apresentam-se com intensidade menor que em 6/11/98 devido ao menor nível de radiação no inverno e, conseqüentemente, menor fluxo de energia para os níveis inferiores do solo. Em ambos os ciclos, no período noturno, os valores de FCS foram maiores no meio externo que no interno em função das maiores perdas de energia para a atmosfera, que no meio interno diminui devido à contra-irradiação do polietileno.

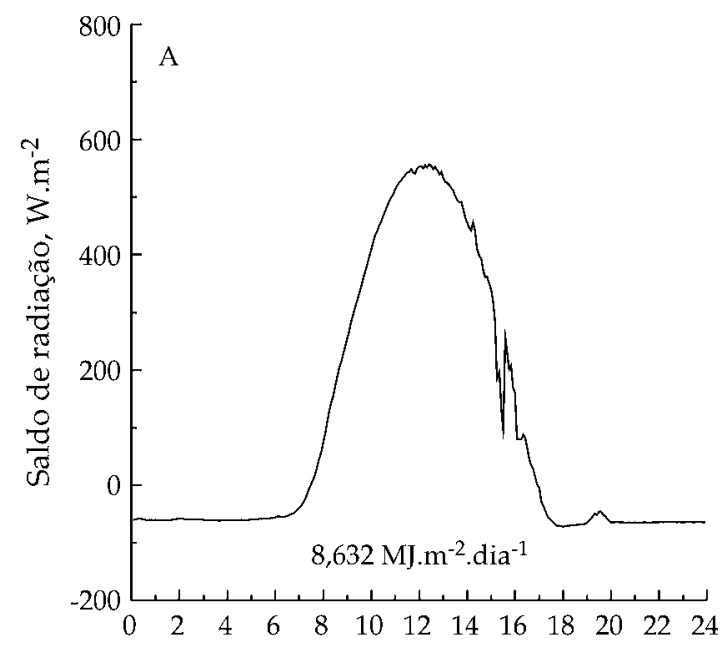

\subsection{Saldo de radiação em período de inverno}

O saldo de radiação integrado ao longo do ciclo da cultura de pepineiro resultou em valores de 693,68 e 808,04 MJ.m.2 (Figura 5), nas condições interna e externa respectivamente, evidenciando uma relação SRint/SRext de 85,9\%.

Observa-se em dias com baixa energia (dias nublados) que os valores de saldo de radiação são tendencialmente mais elevados no interior da estufa; nesses dias a emissão efetiva noturna é menor, resultando, portanto, em valores menos negativos. Assim, o saldo total (valores positivos menos os valores negativos),

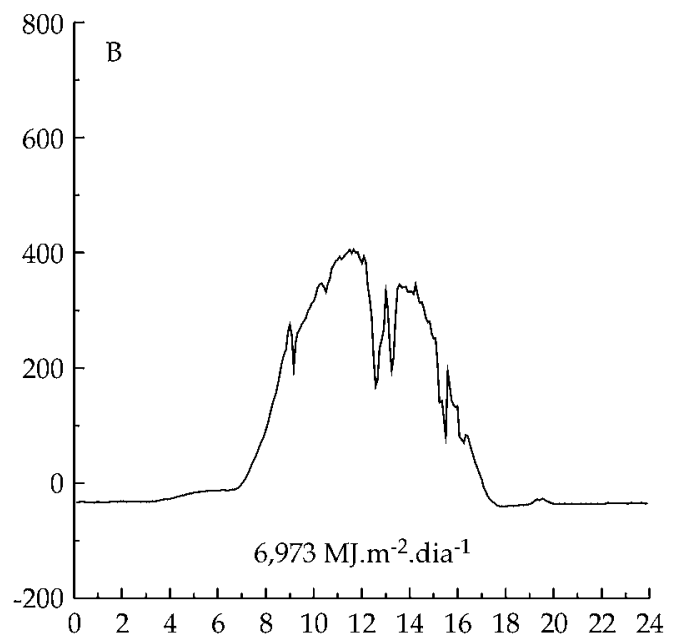

Horas do dia

Figura 2. Curva de saldo de radiação em 21 de maio de 1998, em Botucatu (SP), em condições externa (A) e interna (B) da estufa com cobertura de polietileno.
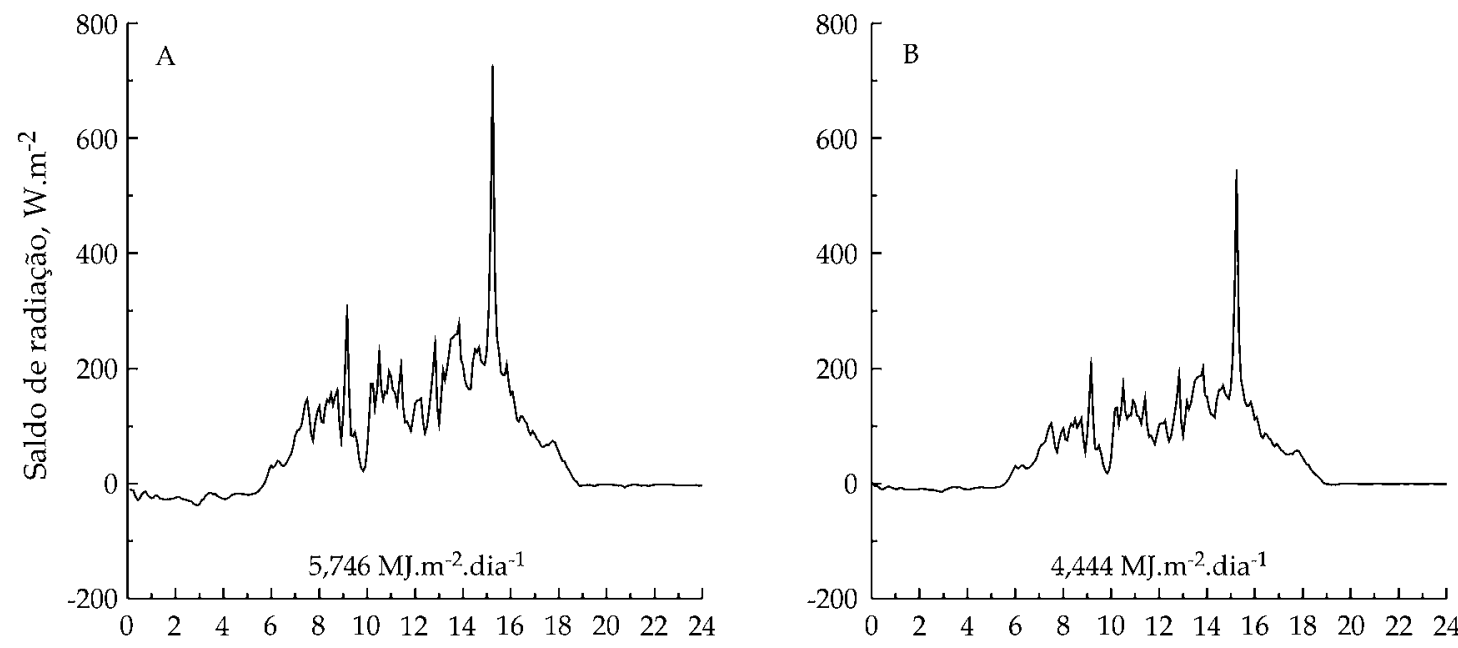

Horas do dia

Figura 3. Curva de saldo de radiação em 25 de dezembro de 1998, em Botucatu (SP), em condições externa (A) e interna (B) da estufa com cobertura de polietileno, fase de máximo crescimento vegetativo da cultura de pepineiro em dia nublado. 

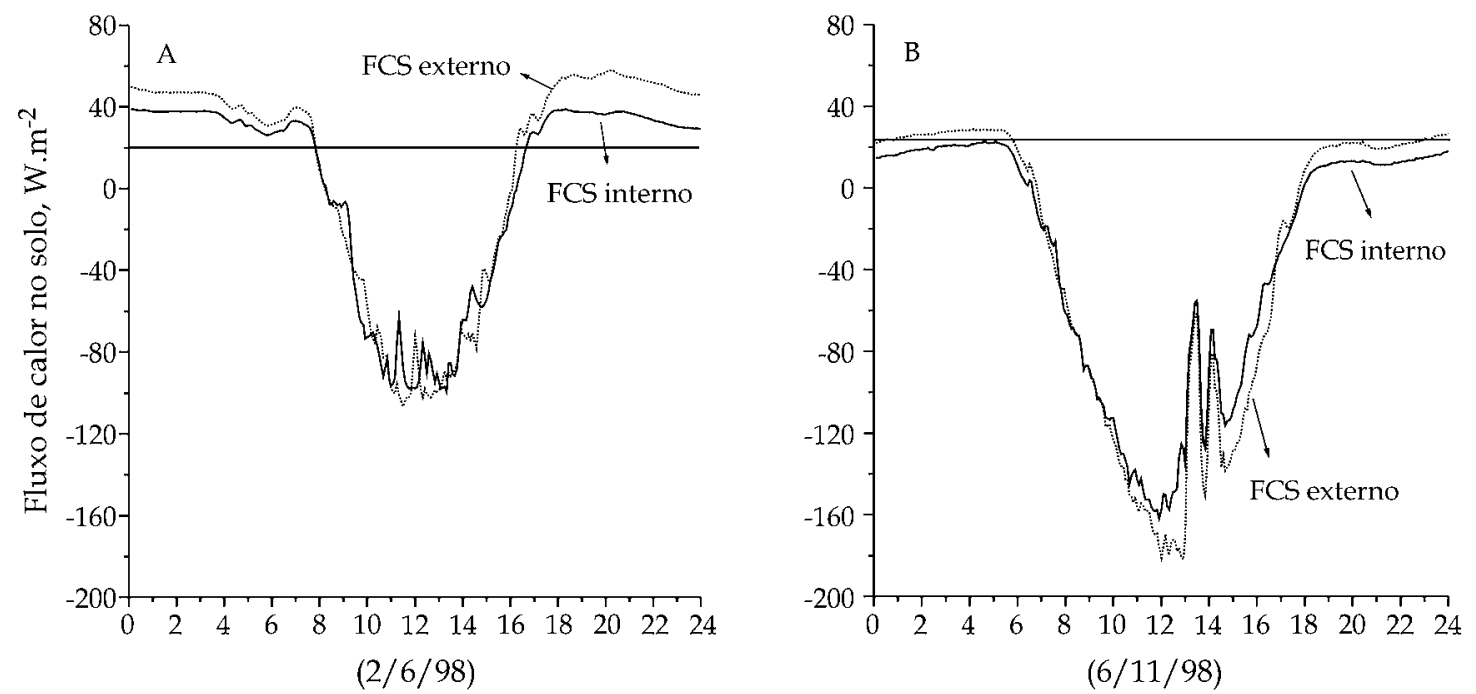

Figura 4. Fluxo de calor do/para o solo em 2/6/98 (A) e 6/11/98 (B) para as condições interna e externa da estufa com cobertura de polietileno.

em geral, é maior em condição interna da estufa com cobertura de polietileno.

Ainda na figura 5, observa-se a diminuição do saldo de radiação no final de junho e início de julho e a elevação a partir desses meses. Tal curva associa-se ao inverso da curva de declinação solar, mostrando no mês de junho (solstício de inverno, 21 de junho) os mínimos de energia para essa latitude.

Ao relacionar os valores integrados $\left(\mathrm{MJ} . \mathrm{m}^{-2}\right)$ do saldo de radiação em condição interna a partir de medidas externas (SRext) e da radiação global externa (Gext) e interna (Gint), obtiveram-se os seguintes modelos:

$$
\begin{array}{ll}
\text { SRint }=0,362+0,804 . \text { SRext } & \left(\mathrm{r}^{2}=0,93, \mathrm{n}=121\right) \\
\text { SRint }=0,055+0,427 . \text { Gext } & \left(\mathrm{r}^{2}=0,85, \mathrm{n}=121\right) \\
\text { SRint }=-0,251+0,636 . \text { Gint } & \left(\mathrm{r}^{2}=0,90, \mathrm{n}=121\right) \\
\text { SRint }=0,612 . \text { Gint } & \left(\mathrm{r}^{2}=0,90, \mathrm{n}=121\right) \\
\text { SRext }=0,502 . \text { Gext } & \left(\mathrm{r}^{2}=0,83, \mathrm{n}=121\right)
\end{array}
$$

Os dois últimos modelos apresentaram a relação entre a radiação global e o saldo de radiação médio para o ciclo de inverno e verão de 0,612 e 0,502 respectivamente. SENTELHAS et al. (2000), em Piracicaba (SP), obtiveram a relação 0,57 para as condições de gramado. Observa-se, em condição externa ao ambiente protegido, que o saldo de radiação representa, em média, 50,2\% da radiação global e, em condição interna, esse valor é $61,2 \%$; tal diferença estáassociada à contra-irradiação do polietileno ao componente de radiação refletida e emitida pelo dossel da cultura, conforme discutido anteriormente.

\subsection{Saldo de radiação em cultivo de verão}

O saldo de radiação integrado ao longo do ciclo de verão édemonstrado na figura 6 . Os totais integrados representaram 982,39 e $1.223,63$ MJ.m ${ }^{-2}$, nas condições interna e externa respectivamente, conferindo uma relação SRint/SRext de 80,3\%. Contrário ao ciclo de inverno, não se observou nenhuma tendência em relação à declinação solar, pois o sol, nessa época do ano, encontrava-se em sua declinação máxima para o hemisfério sul $\left(-23^{\circ} 27^{\prime}\right)$, coincidindo em parte do ciclo com a latitude do local $\left(-22^{\circ} 51^{\prime}\right)$.

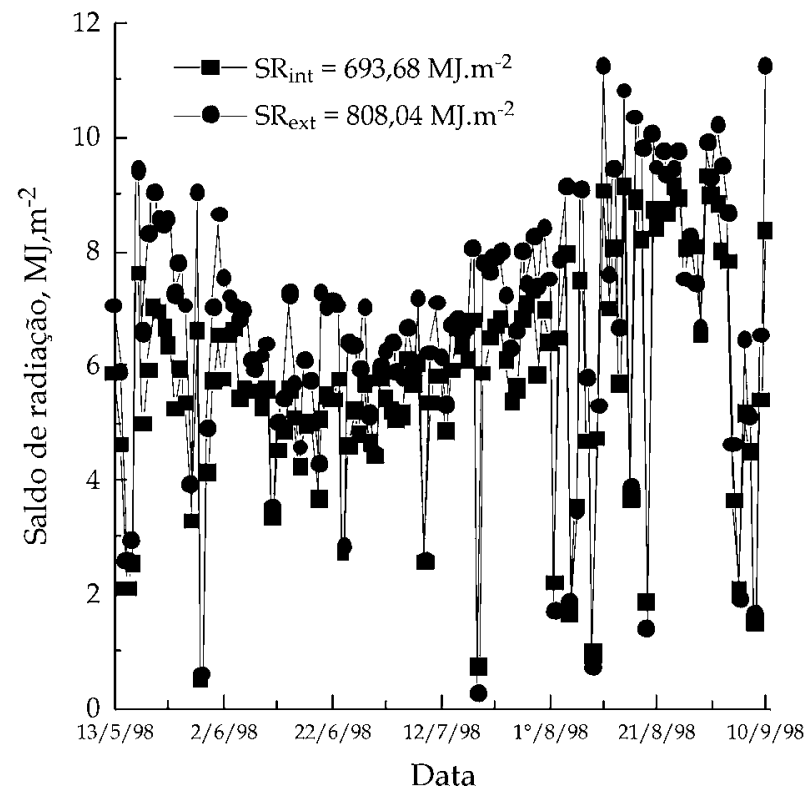

Figura 5. Variação do saldo de radiação ao longo do ciclo de inverno na cultura de pepineiro dentro (SRint) e fora (SRext) da estufa com cobertura de polietileno. 


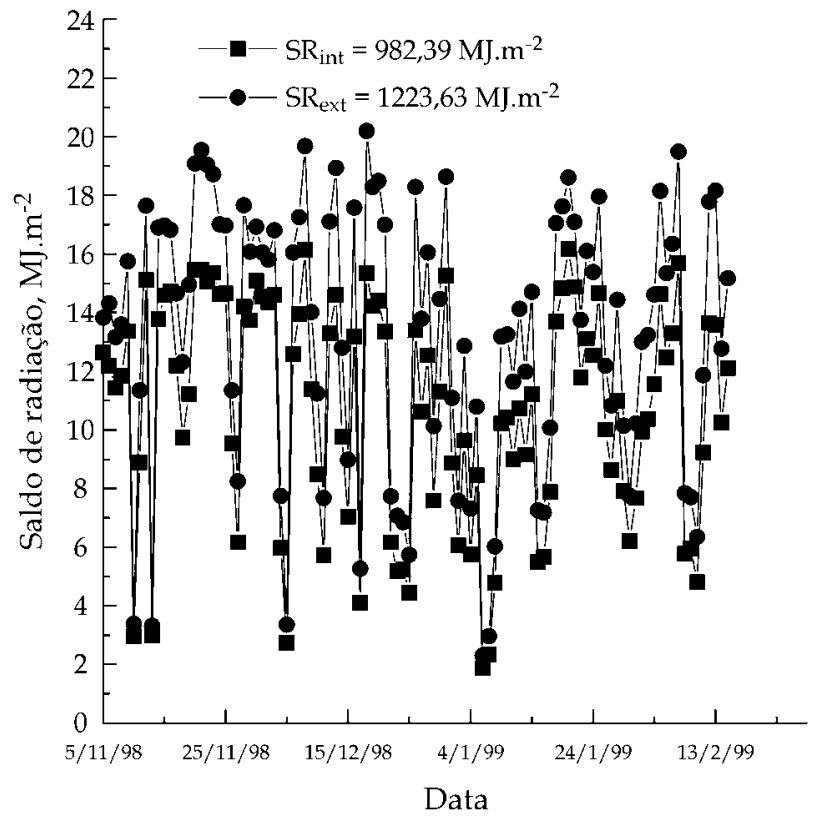

Figura 6. Variação do saldo de radiação ao longo do ciclo da cultura de pepineiro, cultivado no verão, dentro (SRint) e fora (SRext) da estufa com cobertura de polietileno.

Relacionando-se, mediante regressão linear, o saldo de radiação medido em condição interna (SRint) com aqueles obtidos externamente (SRext) e, o saldo de radiação com a radiação global externa (Gext) e interna (Gint), encontram-se as seguintes relações:

$$
\begin{array}{ll}
\text { SRint }=-0,304+0,828 . \text { SRext } & \left(r^{2}=0,97, n=103\right) \\
\text { SRint }=0,177+0,525 . \text { Gext } & \left(r^{2}=0,98, n=103\right) \\
\text { SRint }=0,741+0,657 . \text { Gint } & \left(r^{2}=0,98, n=103\right)
\end{array}
$$

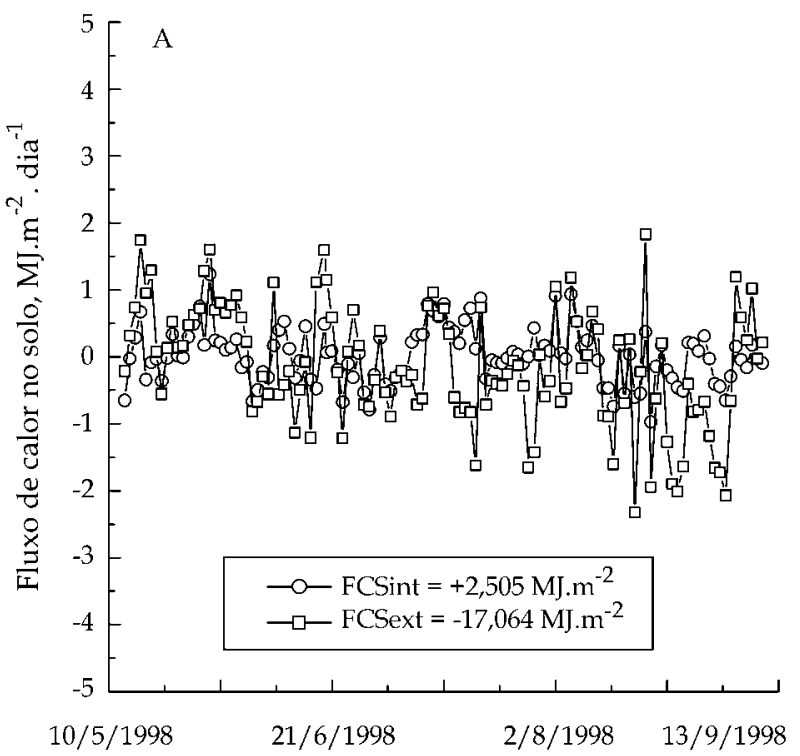

$$
\begin{array}{ll}
\text { SRint }=0,70 . \text { Gint } & \left(r^{2}=0,97, n=103\right) \\
\text { SRext }=0,66 . \text { Gext } & \left(r^{2}=0,95, n=103\right)
\end{array}
$$

Oliver e Sene (1992), analisando o saldo de radiação e radiação global em culturas de videiras no Sul da Espanha, encontraram a relação $\mathrm{SR}_{\mathrm{ext}}\left(\mathrm{W} \cdot \mathrm{m}^{-2}\right)$ $=0,57 \cdot G_{\text {ext }}\left(W \cdot m^{-2}\right)-59,0\left(r^{2}=0,986\right)$. Segundo os autores, para a mesma região em condição de campo limpo (arado), obteve-se a seguinte relação: SR ext $\left(W \cdot m^{-2}\right)=0,59 \cdot G_{\text {ext }}\left(W \cdot m^{-2}\right)-60\left(r^{2}=0,950\right)$.

\subsection{Fluxo de calor para o solo em período de inverno e verão}

O ciclo de inverno apresentou valores integrados ao longo do ciclo em condições interna e externa: $+2,505$ e $-17,064$ MJ.m ${ }^{-2}$ respectivamente. Valores negativos indicam que o fluxo de energia foi para o solo e, os positivos, para a atmosfera.

A figura 7B mostra a curva de fluxo de calor no solo (FCS) no ciclo do verão. Os valores de FCS interno foram de-68,90 MJ.m ${ }^{-2}$ e o externo, $-11,45 \mathrm{MJ} \cdot \mathrm{m}^{-2}$. Observa-se que, até $30 / 12$, o FCS foi função do saldo de radiação oscilando na mesma proporção que este. Contudo, quando se forma um dossel homogêneo da cobertura vegetal, observam-se pequenas variações dos valores de FCS devido ao sombreamento do solo, diminuindo os níveis de radiação, verificadas pelas curvas de índice de área foliar (Figura 8). Após a retirada da cultura em 10/2/98, os valores de FCS voltam a ser função do saldo de radiação disponível.

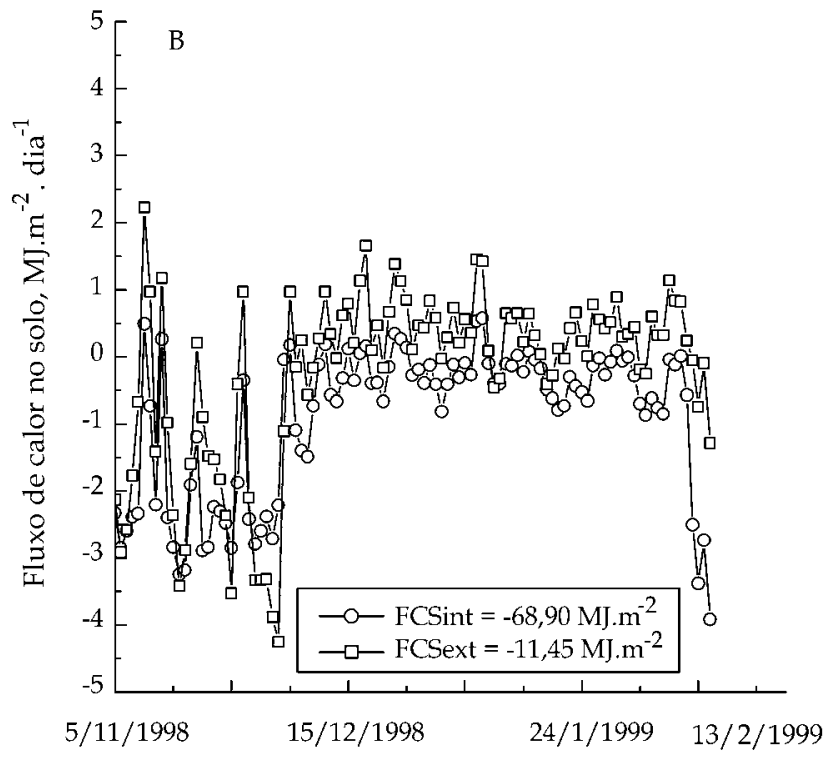

Figura 7. Fluxo de calor do/para o solo nas condições interna (FCSint) e externa (FCSext) da estufa com cobertura de polietileno para os ciclos de inverno (A) e verão (B). 


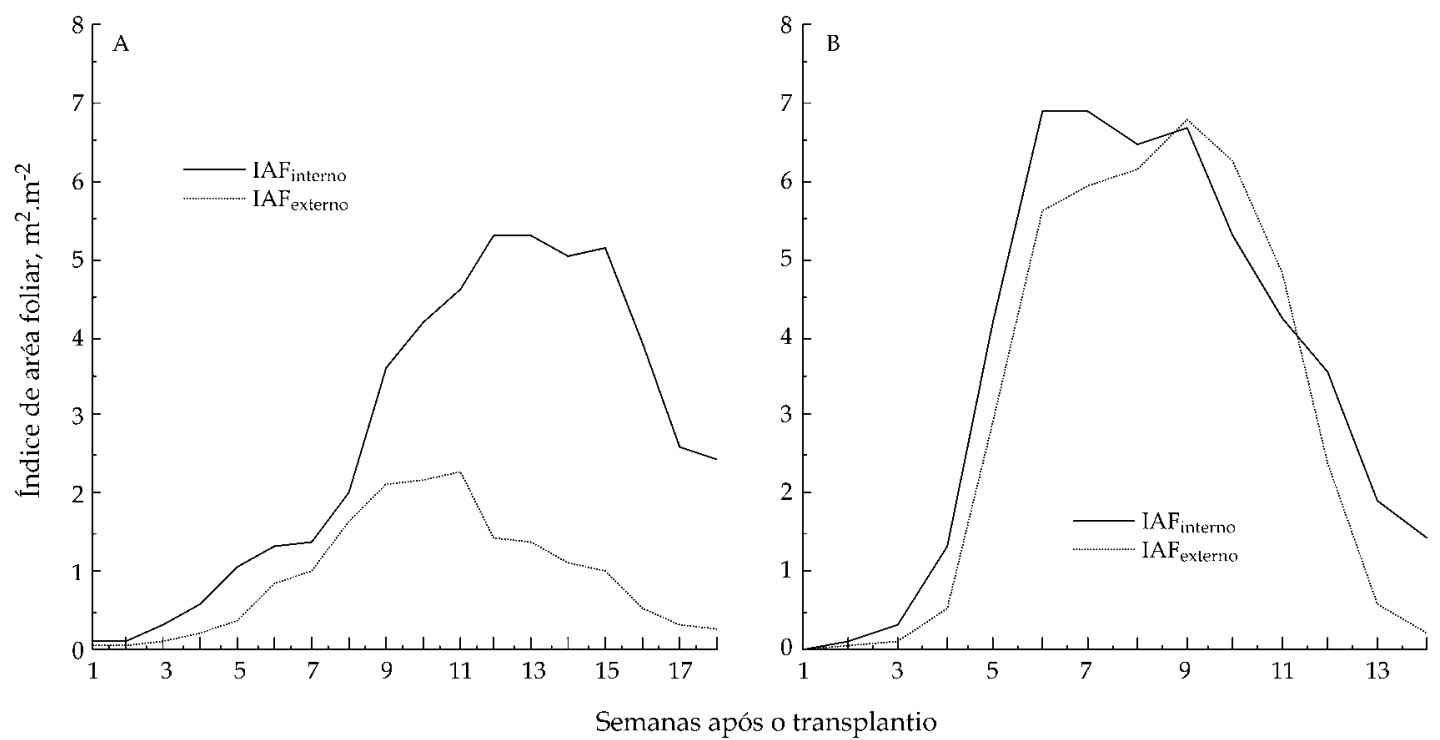

Figura 8. Índice de área foliar em condições interna (IAFinterno) e externa (IAFexterno), em casa de vegetação, ciclos de inverno (A) e verão (B) em semanas após o transplantio.

\subsection{Radiação global}

A figura 9 apresenta uma curva da irradiância solar global ao longo do dia 21 de maio de 1998 (com ausência de nuvens), observando-se máxima intensidade de energia de 712,47 e 534,82 W.m ${ }^{-2}$ às 12 h nos dois ambientes. Dividindo-se a intensidade máxima interna e externa da estufa, obtém-se a transmissividade máxima para este dia de 75,0\%. Verificam-se picos de menor irradiância, resultado do sombreamento dos sensores pelos arcos metálicos da estufa.

Ao relacionar, mediante regressão linear, os valores de energia (MJ. $\mathrm{m}^{-2}$ ) obtidos em condição interna e externa, encontram-se modelos, representados a seguir, que permitem conhecer o valor da energia interna da estufa a partir daqueles medidos externamente (Figura 10).

$$
\begin{array}{r}
\text { Gint }=+0,271+0,687 \text {. Gext } \\
\left(r^{2}=0,986, n=121\right)-\text { inverno }
\end{array}
$$

$$
\begin{aligned}
& \text { Gint }=0,706 \text {. Gext } \\
& \qquad\left(r^{2}=0,985, n=121\right)
\end{aligned}
$$

$$
\begin{aligned}
& \text { Gint }=-0,766+0,794 \text {. Gext } \\
& \qquad\left(r^{2}=0,996, n=103\right) \text { - verão }
\end{aligned}
$$

Gint $=0,760$. Gext

$$
\left(\mathrm{r}^{2}=0,994, \mathrm{n}=103\right)
$$

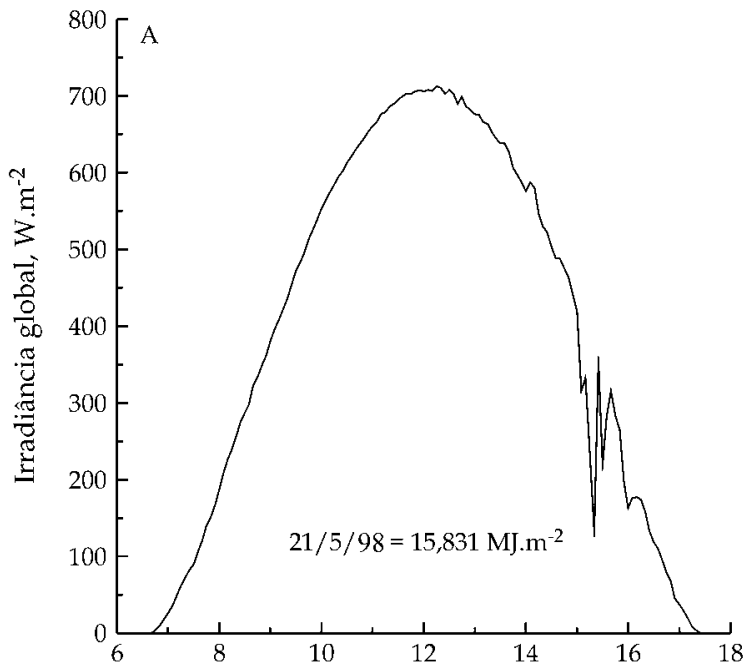

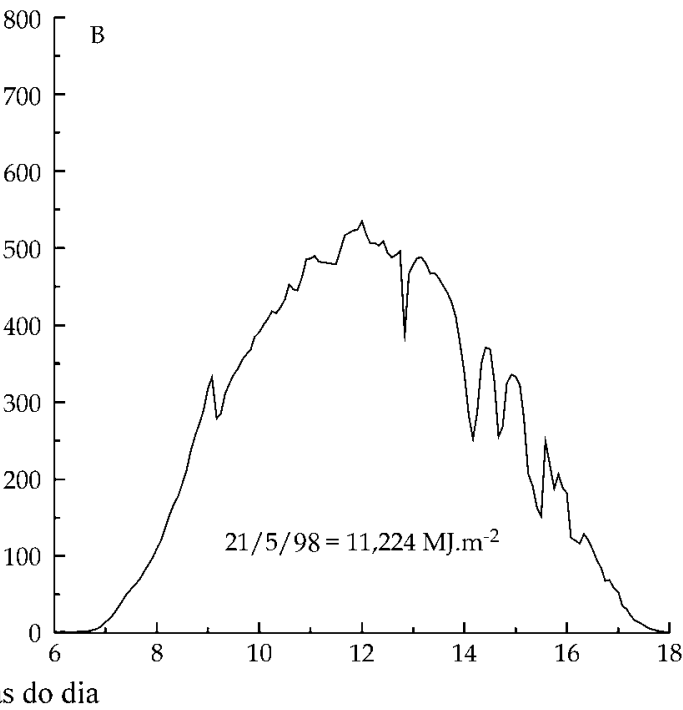

Figura 9. Curva de irradiância (W.m ${ }^{-2}$ ) para o dia 21 de maio de 1998, em Botucatu (SP), monitorada com piranômetros, nas condições externa (A) e interna (B), em estufa com cobertura de polietileno. 

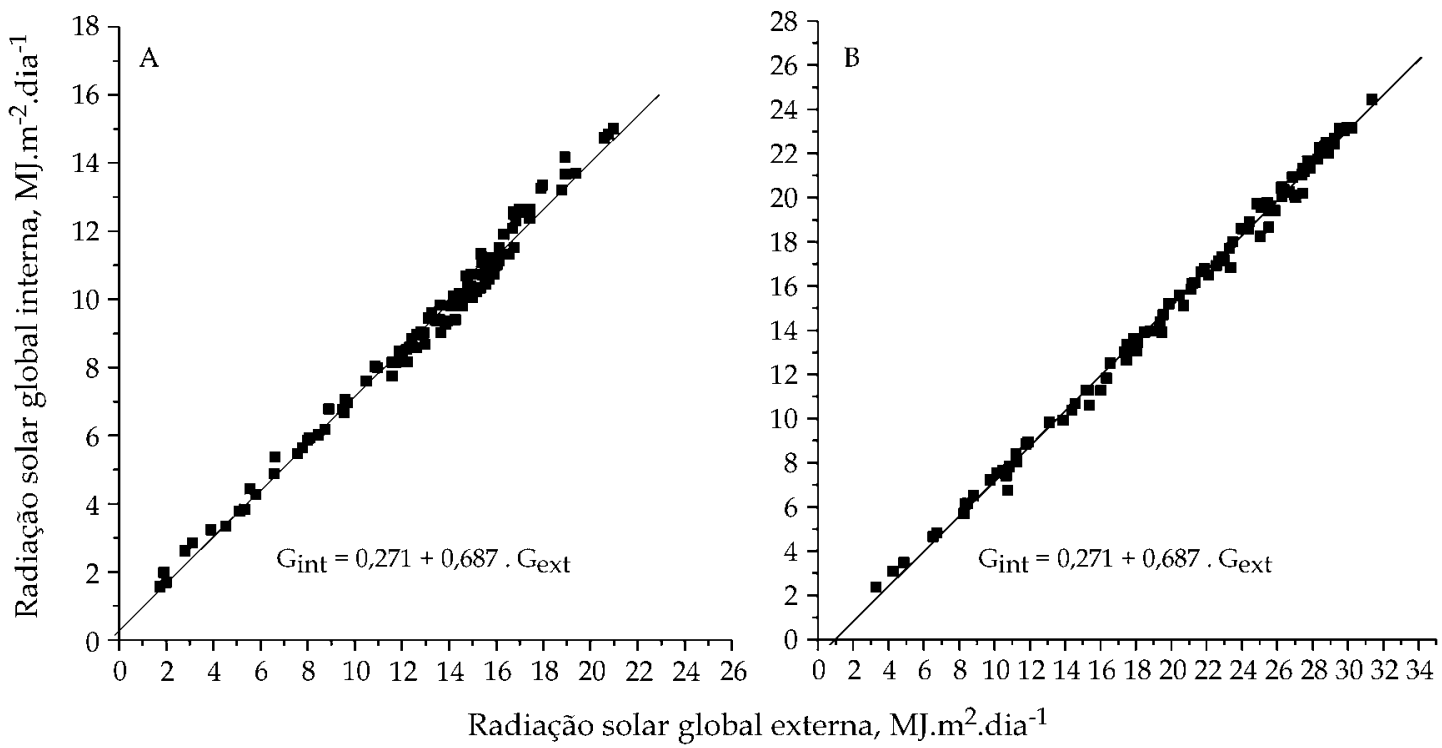

Figura 10. Relação entre radiação solar global interna e externa em ambiente protegido, nos ciclos de outono-inverno (A) e primavera-verão (B).

A transmissividade do polietileno, calculada pela relação entre a radiação solar global interna e externa para todo o período, revelou valores de $70,8 \%$ no inverno e $74,9 \%$ no verão, diferenciando um pouco daqueles calculados pelo coeficiente angular da reta de regressão.

GALVANI et al. (1998b) observaram em estufas de polietileno, cultivadas com alface, uma transmissividade de $78,3 \%$ e $73,6 \%$ para as orientadas a leste-oeste e ao norte-sul respectivamente. Utilizando-se dessa mesma orientação para as estufas, os autores encontraram as respectivas transmissividades: $85,6 \%$ e $83,9 \%$, quando considerado o saldo de radiação de ondas curtas.

\section{CONCLUSÕES}

1. A estufa com cobertura de polietileno diminuiu a intensidade da incidência de energia solar por unidade de área no período diurno e, também, as perdas por emissão à noite.

2. A transmissividade do polietileno à componente de radiação global variou em função da época do ano: $70,8 \%$ no inverno e $75,0 \%$ no verão.

3. O fluxo de calor do/para o solo foi dependente da cobertura de solo pela cultura.

4. Estimou-se, com boa precisão, o saldo de radiação em meio interno a partir do saldo de radiação e da radiação solar global externa.

\section{AGRADECIMENTOS}

O primeiro autor agradece à Fundação de Amparo à Pesquisa do Estado de São Paulo (FAPESP) pelos recursos financeiros - processo n. 96/08974-7.

\section{REFERÊNCIAS BIBLIOGRÁFICAS}

AZEVEDO, P.V.; TEIXEIRA, A.H. de C.; SILVA, B.B. da.; SOARES, J.M.; SARAIVA, F.A.M. Avaliação da reflectância e do saldo de radiação sobre um cultivo de videira européia. Revista Brasileira de Agrometeorologia, Santa Maria, v.5, n.1, p.1-7, 1997.

BURIOL, G.A.; SCHNEIDER, F.M.; STEFANEL, V.; ANDRIOLO, J.L.; MEDEIROS, S.L.P. Modificação na temperatura mínima do ar causada por estufas de polietileno transparente de baixa densidade. Revista Brasileira de Agrometeorologia, Santa Maria, v.1, n.1, p.43-49, 1993.

GALVANI, E.; ESCOBEDO, J.F.; FRISINA, V. de A. Estimativa das irradiâncias global, saldo de radiação e de ondas curtas em cultura de alface (Lactuca sativa L.) em casas de vegetação orientadas L-O e N-S. In: CONGRESSO BRASILEIRO DE BIOMETEOROLOGIA, 2., 1998, Goiânia. Anais.... Goiânia: Sociedade Brasileira de Biometeorologia, 1998a, p.209-215.

GALVANI, E.; ESCOBEDO, J.F.; FRISINA, V. de A. Estimativa de saldo de radiação e de ondas curtas a partir de irradiância global externa sobre cultura de alface ( $L a c-$ tuca sativa L.) em condição de casas de vegetação orientadas no sentido L-O e N-S. In: CONGRESSO BRASILEIRO DE METEOROLOGIA, 10., 1998, Brasília. Anais... (CD-ROM). Brasília: Sociedade Brasileira de Meteorologia, 1998b. 
GEIGER, R. Manual de microclimatologia: o clima da camada de ar junto ao solo. 3.ed. Lisboa: Fundação Calouste Gulbenkian, 1961. 556p.

MONTEITH, J.L.; UNSWORTH, M.H. Principles of environmental physics. 2.ed. London: Edward Arnald, 1990. 291p.

OLIVER, H.R.; SENE, K.J. Energy and water balances of developing vines. Agricultural and Forest Meteorology, Amsterdam, v.62, p.167-185, 1992.

PEZZOPANE, J.E.M.; PEDRO JÚNIOR, M.J.; ORTOLANI, A.A.; MEYER, N. Radiação líquida e temperatura de folha no interior de estufa com cobertura plástica, durante o período noturno. Revista Brasileira de Agrometeorologia, Santa Maria, v.3, p.1-4, 1995.

ROBLEDO DE PEDRO, F.;VICENTE, L.M. Aplicación de los plasticos en la agricultura. 2.ed. Madrid: Mundi-Prensa, 1988. 573p.

SENTELHAS, P.C.; PEREIRA, A.R.; ANGELOCCI, L.R. Meteorologia Agrícola. Piracicaba: Departamento de Física e Meteorologia, ESALQ/USP, 1998. 131p. (apostila)

TAPIA, G.J. Filmes térmicos para invernaderos. Revista de los plásticos modernos, Madri, v.295, p.75-82, 1981. 